\section{in the final analysis}

"The order I'm about to sign does two things. First, it orders a 100-day review of four vital products: semiconductors-one; key minerals and materials, like rare earths, that are used to make everything from harder steel to airplanes; three, pharmaceuticals and their ingredients; four, advanced batteries, like the ones used in electric vehicles."

\section{JOM}

Volume 73

Number 8

August 2021

Interesting data point: About $15 \%$ of TMS professional members are engaged in the direct support of U.S. government priorities by working for national laboratories, for a branch of the military, for a wide range of agencies, or for another entity. Beyond the work conducted on government premises, there is also the reach and impact of those research dollars issued annually to investigators at universities, industries, and even the occasional professional society. Whether one lives inside or outside of the United States, the scope of the federally funded research enterprise has impact worldwide.

One of the ways that TMS represents its membership is by offering more "material" for informed federal discussion about science and technology. TMS helps inform decision makers by making periodic visits to Washington, D.C., and conversing with legislators, their staff members, and representatives of the President's administration. Historically, we've done this in person. Last year, we didn't do it at all (because of the pandemic and other distractions impacting the capitol city). In Spring 2021, we rebounded and "Zoomed" with two Senators offices, two House of Representatives offices, the House of Representatives Science Committee, and the White House's Office of Science and Technology Policy. Participating from TMS were TMS President Ellen Cerreta, immediate TMS Past President Thomas Battle, Public \& Governmental Affairs Director Eric Brown, and the author of this column.

By its nature, TMS is a nonpartisan and apolitical organization. Our visits and positions are never in support of individual politicians or political parties. We stay high level and focus on the importance of science and technology and informed legislation. Bottom line: We think that materials are critical to our economic well-being, quality of life, and standard of living. So, what did we talk about during this year's visits?

- We advocated for an increase of funding for the National Science Foundation (NSF). Both the Senate and the House of Representatives were working on legislation at the time that would do this, and we expressed support for NSF growth to survive within whatever legislation would eventually be adopted.

- We advocated for funding projects to rebuild and modernize our infrastructure. Existing and new materials technologies as well as recycling have roles to play. Again, multiple bills were being discussed. We didn't recommend winners, only that whatever legislation is adopted address hard infrastructure.

- We advocated in support of legislative language that would fill the STEM (science, technology, engineering, and mathematics) pipeline and that these efforts be mindful of supporting the inclusion of underrepresented groups while advancing diversity, equity, and inclusion. We also underscored our support of the need for racial justice.

- We advocated to protect the peer-review process by maintaining a 12-month embargo before the mandatory conversion to open access of federally funded technical papers.

Did our visits have impact? I'm a pragmatist with a lean toward optimist, so I like to think "yes." If nothing else, just making the effort to visit an office creates an opportunity to imprint with officials, especially if you do it with forthrightness and grasp of the issues and without partisanship and bias. We can't take credit, but it was encouraging to see the Biden administration, a week after our visits, single out three materials sectors for immediate attention in improving the supply chain: Lithium batteries, critical materials and rare earths, and semiconductors. As with the startup of the Materials Genome Initiative a decade ago, it is gratifying to see materials so prominent on the White House agenda. More, please.

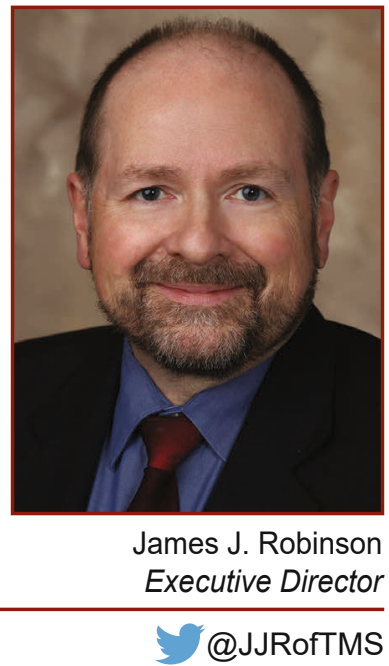

"TMS helps

inform decision makers by making

periodic visits to

Washington, D.C., and conversing with

legislators, their

staff members, and representatives of the President's administration." 